\title{
A MARGINALIDADE DOS ESTUDOS DE GÊNERO NAS CIÊNCIAS DA RELIGIÃO
}

\author{
Priscila Neves Moreira*
}

\section{RESUMO}

O presente artigo origina-se da experiência da autora, enquanto mestranda do Programa de Pós-Graduação em Ciências da Religião. Através de uma breve revisão bibliográfica, constata-se que os autores utilizados como referenciais clássicos na disciplina de Introdução às Ciências da Religião são apenas do sexo masculino e não utilizam a categoria de gênero na análise dos fenômenos religiosos. Fazendo uso das reflexões propostas por pesquisadoras da área de gênero e religião, busca-se refletir sobre a marginalidade de tais estudos nas ciências em geral e especificamente nas Ciências da Religião. Finalmente, acredita-se que essa breve pesquisa possa contribuir para uma escolha de bibliografia mais igualitária e crítica no que diz respeito à Introdução às Ciências da Religião.

Palavras-chave: Estudos de Gênero; Ciências da Religião; Estudos Feministas.

\section{THE MARGINALITY OF GENDER STUDIES IN THE SCIENCES OF RELIGION}

\section{ABSTRACT}

This article originates from the author's experience as a Master's student of the Graduate Program in Sciences of Religion. Through a brief literature review, it can be seen that the authors used as classical references in the subject Introduction to Sciences of Religion are only male and do not use the gender category in the analysis of religious phenomena. Using the reflections proposed by researchers

* Mestranda em Ciências da Religião na Universidade Metodista de São Paulo. Graduada em Psicologia pela Universidade Federal Fluminense, especialista em Psicologia Clínica pelo Instituto Superior do CENSA. 
in the area of gender and religion, we seek to reflect on the marginality of such studies in the sciences in general and specifically in the sciences of religion. Finally, it is believed that this brief research may contribute to a more egalitarian and critical choice of bibliography regarding the Introduction to Sciences of Religion.

Keywords: Gender Studies; Sciences of Religion; Feminist Studies.

\section{LA MARGINALIDAD DE LOS ESTUDIOS DE GÉNERO EN LAS CIENCIAS DE LA RELIGIÓN}

\section{RESUMEN}

Este artículo se origina en la experiencia del autor como estudiante de maestría del Programa de Posgrado en Ciencias de la Religión. A través de una breve revisión de la literatura, se puede ver que los autores utilizados como referencias clásicas en el tema de Introducción en Ciencias Religiosas son solo hombres y no usan la categoría de género en el análisis del fenómeno religioso. Utilizando las reflexiones propuestas por los investigadores en el área de género y religión, buscamos reflexionar sobre la marginalidad de tales estudios en las ciencias en general y específicamente en las ciencias de la religión. Finalmente, se cree que esta breve investigación puede contribuir a una elección de bibliografía más igualitaria y crítica con respecto a la Introducción a las Ciencias Religiosas.

Palabras clave: Estudios de género; Ciencias de la religión; Estudios feministas.

\section{INTRODUÇÃO}

A despeito do que se buscou durante muito tempo na tradição filosófica ocidental, o conhecimento não é neutro, nem tampouco isento de influências culturais, sociais e históricas. Todo conhecimento é datado e localizado, ou seja, diz respeito ao tempo e local em que foi produzido.

O reconhecimento desse fato ainda não se dá sem resistência por parte de muitos integrantes da academia científica. Ainda há quem se interesse em definir certa imparcialidade a fim de garantir que determinados conceitos possam estar acima dos processos históricos e, portanto, serem reconhecidos como verdades inequívocas e universais.

Em sua obra "Eros e os processos cognitivos", Robin Schott (1996) investiga a evolução dos conceitos filosóficos e seu entrelaçamento 
com concepções negativas do corpo e das mulheres. De acordo com a autora, não é por acaso que foi negado às mulheres o saber filosófico.

Começando na filosofia de Platão e Aristóteles, o corpo foi considerado fonte de corrupção, ao qual as mulheres eram associadas. Essa associação era baseada também nas práticas sociais e filosóficas que vinculavam o ser feminino com as práticas corporais pecaminosas que se colocavam como obstáculo para o conhecimento filosófico verdadeiro. Dessa forma, era justificável que a filosofia se restringisse apenas aos homens, pois a sexualidade que estava atrelada ao corpo feminino representava um obstáculo para a razão e por isso os homens também eram orientados a se absterem do contato sexual com as mulheres (Robin SCHOTT, 1996).

A religião, enquanto geradora de sistemas simbólicos, também teve sua contribuição no controle dos corpos e nos processos cognitivos das sociedades. Por muito tempo, os homens, na posição de autoridades religiosas, detiveram o poder de dizer as verdades sobre o mundo e as pessoas. Estas foram grandes responsáveis pela vinculação do corpo feminino ao pecado e à transgressão e, dessa forma, institucionalizou-se a crença de que as mulheres eram seres inferiores, aquém de qualquer conhecimento considerado legítimo e verdadeiro (Ivone GEBARA, 1997).

Por isso, quando se analisa a exclusão das mulheres dos espaços de poder, como por exemplo, universidades, templos religiosos, mercado de trabalho etc, é de suma importância analisar a influência da religião, uma vez que ela fundamenta a vida da sociedade e atribui sentido para a vida da maioria das pessoas.

\section{BREVE INTRODUÇÃO À CIÊNCIA DA RELIGIÃO}

Estudar a religião pode parecer uma tarefa ambígua uma vez que, de acordo com os princípios modernos, ciência e religião se contradizem. Apesar da resistência dos detentores do saber, houve quem se dedicasse a pesquisar o fenômeno religioso, suas manifestações e efeitos sociais.

A escolha das fontes clássicas em Ciências da Religião destaca nomes como Sigmund Freud (1978), que considerava a religião como uma ilusão que seria superada conforme as sociedades se desenvolvessem. Karl Marx (1979) que compreende a religião como uma ferramenta do 
sistema que contribui para a alienação das classes ao mesmo tempo que propicia às pessoas certo alívio para enfrentar a realidade e, por isso, a define como "ópio do povo".

Mircea Eliade (1977), um importante pesquisador das religiões, parte de outra perspectiva. Para ele o mundo é repleto de resquícios do sagrado e se dedica então a estudar as formas de manifestação do sagrado que está sempre articulado na cultura e na história. Ele se interessa pelo estudo dos mitos, e acredita que eles contam histórias verdadeiras, explicando o porquê de as coisas serem como são.

Umberto Galimberti (2003) propõe uma forma de compreender o sagrado que se atrela à Psicanálise, relacionando o sagrado ao inconsciente, ou seja, aquilo que escapa à razão. Para Galimberti, quando se racionaliza o sagrado, se desaprende a lidar com ele. Os seres humanos, contudo, abandonaram o sagrado e voltaram-se para a técnica, para o explicável e previsível, fazendo com que se afastem daquilo que lhes é mais profundo: o inconsciente.

Esses autores exemplificam como a religião vem sendo abordada enquanto objeto de estudo das ciências. Cada autor analisa esse fenômeno de forma peculiar e captam, cada qual a seu modo, a complexidade das religiões e sua importância nos diferentes contextos históricos e sociais.

Nenhum desses, contudo, se interessa pela questão de gênero e pelas questões das mulheres.

\section{OS ESTUDOS FEMINISTAS E DE GÊNERO'}

O século XX trouxe consigo importantes mudanças nas representações históricas sobre as mulheres e seus corpos. Foi nessa época que começaram a se discutir os direitos reprodutivos, a violência sofrida por mulheres no ambiente doméstico, a inserção das mulheres no mercado de trabalho, etc. Esses acontecimentos provocaram também sérios questionamentos na forma tradicional de se fazer ciência (Ivone GEBARA, 2007).

A inserção dos estudos feministas e dos estudos de gênero produziram novos questionamentos e reformulações na forma tradicional de produção do saber. O saber sempre foi produzido de forma androcên-

Nesse artigo os termos Estudos Feministas e Estudos de Gênero serão tratados como sinônimos. 
trica, ou seja, partindo de homens para homens. Dessa forma, são as questões do universo masculino que são respondidas, mostrando que é com esse gênero que a ciência sempre esteve comprometida (Sandra D. de SOUZA, 2015).

Isto acontece também no estudo das religiões, em que a lógica patriarcal se faz presente na

(...) escolha das fontes, dos interlocutores, do quadro teórico e do próprio objeto a ser pesquisado. O processo de produção do saber envolve relações de poder que se traduzem no estabelecimento de uma normatividade que tem raça/etnia, classe, idade e sexo, dentre outro (Sandra D. de SOUZA, 2015, p. 22).

Deve-se considerar, portanto, os sistemas culturais que são legitimados quando se escolhem algumas fontes e não outras; da mesma forma quando a perspectiva de gênero se limita a pequenos comentários nas salas de aula, mas não servem de referencial epistemológico principal e legítimo. Como afirma a pesquisadora Sandra Duarte de Souza (2015), "a negação da autoridade epistêmica das mulheres e a marginalidade de temas de pesquisa voltados para gênero, sexualidade e afins, ainda predomina no masculino universo dos estudos de religião. Masculino desde a sua composição" (p.22).

Os estudos de gênero lançam importantes críticas às categorias universalizantes dos estudos de religião que utiliza conceitos dominantes, sexistas e etnocêntricos na produção do conhecimento.

O fenômeno religioso na ciência ainda é colocado em posição de marginalidade, reflexo da tradição positivista que rejeita a religião como objeto de pesquisa. Para analisar a religião, é importante admitir seu caráter contextual e limitado, assumindo que se trata de

(...) uma construção sócio-cultural. Portanto, discutir religião é discutir transformações sociais, relações de poder, de classe, de gênero, de raça/etnia; é adentrar num complexo sistema de trocas simbólicas, de jogos de interesse, na dinâmica da oferta e da procura; é deparar-se com um sistema sócio-cultural permanentemente redesenhado que permanentemente redesenha as sociedades (Sandra D. de SOUZA, 2004, p. 122-123). 
A forte relação das Ciências da Religião com as instituições religiosas também é um fato decisivo na marginalidade dos estudos de gênero. Essas instituições, produtoras e mantenedoras dos sistemas simbólicos e das identidades de gênero binárias, não estão interessadas em que se problematizem as noções de gênero e as representações de homem e mulher. Dessa forma, a comunidade acadêmica também serviu e serve aos interesses institucionais quando não confere a real importância aos estudos feministas (Sandra D. de SOUZA, 2015).

Os sistemas religiosos são sistemas de sentido, construindo uma cosmovisão generificada orientadora de seus seguidores e seguidoras. As representações religiosas de gênero, na medida em que produzem e reproduzem lugares diferenciados de poder de acordo com o sexo biológico, possuem papel ativo na produção da desigualdade de gênero (Sandra D. de SOUZA, 2015, p. 25-26).

O avanço das pesquisas de gênero mostra o quanto esse campo é instável, pois está entrelaçado às experiências concretas e, justamente por isso, precisa ter um enfoque multi/interdisciplinar. Os estudos feministas forçam o pensamento científico a um certo abandono de objetividades que servem aos mecanismos de opressão baseados nas diferenças de gênero. Se a comunidade acadêmica ainda reluta em aceitar a presença de mulheres como graduandas, pesquisadoras e docentes, é ainda maior sua resistência na reelaboração de suas epistemologias (Sandra D. de SOUZA, 2015).

Vale, portanto, pensar em qual é a contribuição dos estudos feministas nas Ciências da Religião. O que essa epistemologia alternativa tem para oferecer ao que já foi pesquisado? Ivone Gebara (1997), partindo da epistemologia ecofeminista, indica algumas possibilidades:

É preciso captar a religião não apenas a partir da instituição religiosa, mas para além dela e através dos comportamentos que parecem estar fora do controle dos que detém o poder religioso. (...) Tenho me perguntado se aquilo que chamamos "religião" - mesmo num sentido amplo e considerando suas ambiguidades - tem realizado o papel de criar relações, de re-ligar as pessoas entre si, com a Terra, com as forças da natureza. Me pergunto se a religião institucional tem 
desenvolvido comportamentos de consolo, de ternura e misericórdia, se tem ajudado as pessoas a viver seu cotidiano com mais dignidade e a carregar cada vez mais numerosas perguntas sem resposta. No interior desse significado etimológico de "re-ligar", ou "re-ler", a realidade a partir de uma perspectiva de comunhão encontra-se um dos núcleos mais significativos de toda experiência religiosa (Ivone GEBARA, 1997, p. 82).

A teóloga interliga os questionamentos de gênero e as preocupações ecológicas em sua reflexão sobre a religião. Essa perspectiva é de grande relevância na atualidade, com ecossistemas ameaçados e diversas espécies de animais extintas devido à exploração indiscriminada do solo e dos recursos naturais do planeta.

Robin Schott (1996) também oferece uma importante perspectiva de análise quando investiga a história do pensamento filosófico e religioso no que diz respeito ao corpo e às mulheres. Passando pelos filósofos gregos, Santo Agostinho, São Tomás de Aquino e pelos Reformadores, Schott aponta como ascetismo foi sustentando os discursos, de forma que o corpo das mulheres foi atribuído à sexualidade e por isso excluído dos espaços de poder.

Outra importante contribuição é a perspectiva interseccional nos estudos feministas e nos estudos de religião. A interseccionalidade nasce de uma reivindicação, feita principalmente pelas pesquisadoras e pesquisadores negras/os, em considerar não apenas gênero como categoria de análise, mas também classe, raça e etnia.

Maria José Rosado Nunes (2001) aponta que o feminismo conseguiu provocar mudanças reais nos estudos de religião, um exemplo disso é o fato de que uma mulher já foi eleita presidente da American Academy of Religion (Christine Dowing). Isso também tem forçado a academia a incorporar novos referenciais metodológicos em suas pesquisas. Ainda segundo a autora,

Posteriormente, o desenvolvimento de pesquisas de caráter acadêmico, mais analíticas e com bases empíricas, aplicaram ao domínio das religiões, conceitos e métodos de pesquisa feministas. Foi possível assim, avaliar a complexidade das relações existentes no interior do campo religioso. Desvendaram-se os laços ambíguos e contraditó- 
rios das mulheres às religiões e destas às mulheres, no interior das organizações religiosas. A observação empírica mostrou as religiões como espaços sociais complexos, portadores de contradições, que não funcionam sempre e em todas as sociedades como forças conservadoras. Dadas certas circunstâncias, elas podem funcionar como forças mobilizadoras, levando as mulheres a resistir ao seu poder disciplinador (Maria José ROSADO-NUNES, 2001, p. 8-9).

Para além de dissecar o fenômeno religioso, a proposta metodológica feminista tem dado importância para como os rituais e práticas religiosas são moldadas pelas diferenciações sexuais. Por isso, considera-se que, no processo histórico e social de formação das religiões, estas estão entrelaçadas também com as construções de gênero sobre o que é ser mulher e o que é ser homem nos mais diversos contextos (Maria José ROSADO-NUNES, 2001).

A perspectiva pós-colonial tem representado outra mudança de paradigmas no que diz respeito à pesquisa sobre gênero e religião. Considerando os efeitos da hegemonia europeia nos diversos países colonizados, busca-se exercitar epistemologias mais emancipatórias que não se baseiem em pressupostos normativos coloniais.

Inserindo a categoria de gênero na reflexão pós-colonial, é importante abandonar os essencialismos atribuídos às mulheres, como se fossem sujeitos homogêneos ou colocando todas na categoria de vítimas. No processo de colonização as mulheres também foram ativas do lado opressor e esse reconhecimento não desmerece a crítica feminista.

De acordo com a pesquisadora portuguesa Teresa Martinho Toldy,

(...) a teologia pós-colonial feminista não procura essencializar a mulher: as mulheres estiveram e estão tanto do lado dos colonizados como do lado dos colonizadores e do pensamento colonial. Os binômios (...) colocam mulheres de diferentes geografias, classes e religióes do lado tanto de algumas categorias normativas, como das consideradas "desviantes". E a normatividade imposta a algumas mulheres pode ter sido garantida à custa da normatividade imposta a outras mulheres (e homens). (Teresa TOLDY, 2015, p. 39). 
A autora destaca a importância de centralizar aquilo que é considerado marginal, as teologias e as epistemologias, forçando até mesmo os povos colonizadores a admitir seu racismo, desmascarando o comportamento colonizador ainda presente. As epistemologias e teologias ascéticas devem, portanto, se atentar ao que é produzido pelos que habitam o "não-lugar", pelos que dão ao corpo e à vida outros significados (Teresa M. TOLDY, 2015).

Outro marco importante, especialmente no contexto brasileiro, é a criação da revista Mandrágora, que produz vasto conteúdo relacionando gênero e religião. De acordo com a editora Sandra Duarte de Souza, essa revista busca

(...) revelar no processo de produção simbólico-religioso das instituições tradicionais produtoras de sentido, os esforços dessas instituições no sentido de secundarizar a mulher e, no processo de racionalização da atividade religiosa, negar-lhe lugares de poder baseados em discursos sobre a inferioridade natural da mulher (Sandra D. de SOUZA, 2004, p. 126).

Mesmo após anos de publicações, seminários de pesquisa e militância, a revista Mandrágora ainda enfrenta alguns desafios no contexto de pesquisa brasileiro, a saber: crise de legitimidade, forçando os estudos feministas a se legitimarem em contextos de universidades privadas confessionais que nem sempre se mostram interessados nessa pauta; a especificidade do público alvo, uma vez que muitas pessoas ainda consideram os estudos de gênero e feministas como "assunto de mulher" e quando se relaciona gênero e religião, esse público fica ainda menor (Sandra D. de SOUZA, 2004).

As contribuições exemplificadas apontam para o quão heterogêneo é o campo das pesquisas científicas no que diz respeito a feminismo e gênero. As pesquisadoras e pesquisadores se veem obrigadas/os a dialogar com as mais diversas áreas do conhecimento na tentativa de tentar captar a riqueza dos fenômenos religiosos na perspectiva de gênero, classe e etnia/raça.

Dessa forma, entende-se que não há como utilizar todas essas categorias analíticas sem se render a uma aparente "promiscuidade 
teórica" (Sandra D. de SOUZA, 2015, p. 20) que nem sempre é aderida por quem faz Ciências da Religião. Ainda há uma busca por certa objetividade acadêmica e "pureza" científica que insistem em colocar os estudos feministas e de gênero em local marginal dentro das ciências.

\section{CONSIDERAÇÕES FINAIS}

Os estudos de gênero no âmbito da religião ainda enfrentam diversos desafios: o desinteresse institucional, a resistência dos estudos feministas em falar sobre religião, o uso de categorias analíticas instáveis, o reduzido número de mulheres docentes nos cursos de Teologia e nos Programas de Pós-Graduação em Ciências da Religião, entre outros. Tais desafios se mostram em um contexto em que as mulheres já conseguiram certo espaço na produção acadêmica, porém ainda com muito a ser feito.

Afirmar que os estudos científicos legitimam o sistema patriarcal não significa fazer julgamento de valor sobre as/os pesquisadoras/es que atuam nesse meio, antes de tudo significa reconhecer que esse modo de fazer está alojado na forma de pensar, produzir e ensinar de forma que não se percebe os traços legitimadores da ordem patriarcal.

Gênero como instrumento de análise ainda é considerado apenas mais uma opção e quase sempre se resume a breves comentários ou eventos esporádicos nos programas de pós-graduação, mas ainda não alcançaram o caráter de norteador para uma práxis acadêmica mais igualitária e revolucionária.

Um questionamento a ser feito é sobre a legitimidade dos textos. Quem decide que textos e autores são considerados clássicos? Há, porventura, alguma autonomia das/os atuais pesquisadoras/es nessa decisão? Quando se decide que autores/as são obrigatórios no estudo das religiões parte-se de um lugar mais igualitário ou de uma leitura androcêntrica?

Há inúmeras obras que articulam feminismo/gênero/religião/história que podem ser utilizadas nas ementas de disciplinas de graduação e pós-graduação. Sem dúvida, essas novas bibliografias provocariam mudanças metodológicas e epistemológicas nos cursos.

Conforme as críticas forem sendo de fato acolhidas nos planos de ensino dos Programas de Pós-Graduação em Ciências da Religião, talvez 
possamos encontrar leituras obrigatórias como "Eros e os Processos Cognitivos" (1996) de Robin Schott, "Religião e Sexismo" (1993) de Rosemary Radford Ruether, "Rompendo o Silêncio" (2000) e "Teologia Ecofeminista"(1997) de Ivone Gebara, textos feministas clássicos que podem proporcionar importantes reflexões na disciplina de Introdução às Ciências da Religião.

Esse é um importante passo a ser dado no contexto acadêmico brasileiro atual, em que os conservadorismos de todos os tipos avançam e tentam deslegitimar as lutas feministas e de gênero. Essa atitude também serve de inspiração e motivação para novas/os pesquisadoras/ es que estão se inserindo no mundo da pesquisa científica das religiões.

\section{REFERÊNCIAS}

ELIADE, Mircea. Tratado de história das religiões. Lisboa: Cosmos, 1977.

FREUD, Sigmund. O futuro de uma ilusão. Em: FREUD, Coleção Os Pensadores. São Paulo: Abril Cultural, 1978, p. 85-128.

GALIMBERTI, Umberto. Rastros do Sagrado: o cristianismo e a dessacralização do sagrado. São Paulo: Paulus, 2003.

GEBARA, Ivone. O que é teologia feminista? São Paulo: Brasiliense, 2007.

GEBARA, Ivone. Teologia Ecofeminista. $1^{a}$ ed. São Paulo: Olho d’Água, 1997.

GEBARA, Ivone. Rompendo o silêncio: uma fenomenologia feminista do mal. São Paulo: Vozes, p. 2000.

MARX, Karl; ENGELS, Friederich. Sobre la religión. Salamanca: Sígueme, 1979.

ROSADO-NUNES, Maria José. O impacto do feminismo sobre o estudo das religiões.

Cadernos Pagu, n. 16, Campinas: UNICAMP, 2001. pp. 79-96.

RUETHER, Rosemary Radford. Sexismo e religião: rumo a uma teologia feminista. Sinodal, 1993.

SCHOTT, Robin. Eros e os processos cognitivos: uma crítica da objetividade em filosofia. Rio de Janeiro: Rosa dos Tempos, 1996.

SOUZA, Sandra Duarte de. Estudos Feministas e Religião: percursos e desafios. In: SOUZA, Sandra Duarte de; SANTOS, Naira Pinheiro dos (Orgs.). Estudos Feministas e Religião: tendências e debates. Curitiba: Editora Prismas, São Bernardo do Campo: Universidade Metodista de São Paulo, 2015, p. 13-33.

SOUZA, Sandra Duarte de. Revista Mandrágora: gênero e religião nos Estudos Feministas. Revista Estudos Feministas. Florianópolis v. 12, n. 264 p. 122, jan., 2004. Disponível em: <https://periodicos.ufsc.br/index.php/ref/article/view/S0104-026X2004000300014/9509>. Acesso em: 22 jul. 2019. 
TOLDY, Teresa Martinho. "Passar as fronteiras" Por uma teologia feminista pós-colonial em contexto português: lugares de enunciação. In: SOUZA, Sandra Duarte de; SANTOS, Naira Pinheiro dos (Orgs.). Estudos Feministas e Religião: tendências e debates. Curitiba: Editora Prismas, São Bernardo do Campo: Universidade Metodista de São Paulo, 2015, pp. 35-66.

Submetido em: 3-10-2019

Aceito em: 23-10-2019 